\title{
Design em transformação: uma análise do pensamento e da prática
}

Design in transformation: an analysis of thinking and practice

KOCHHANN, Rafael; Bacharel em Design; UNIVATES Universidade do Vale do Taquari

kochrafa@gmail.com

DAPPER, Sílvia Trein Heimfarth; Doutora em Engenharia; UNIVATES Universidade do Vale do Taquari

silviadesign@gmail.com

\section{Resumo}

O pensamento e a prática em design se transformaram muito no decorrer do tempo. Contudo, a diversidade é o que caracteriza o design, hoje. Esse cenário, entretanto, torna nubladas as responsabilidades das atividades em design. A partir dessa problemática, busca-se maior compreensão acerca das preocupações de acadêmicos em design no que diz respeito, principalmente, aos seus propósitos e às abordagens adotadas. Para isso, foram realizadas entrevistas semiestruturadas no intuito de gerar um panorama da realidade global do design. Após o levantamento dos dados, foram realizadas análises que permitiram criar comparativos entre a narrativa histórica da profissão e os desafios atuais da área. Mediante interpretação das análises, foram obtidos conhecimentos capazes de pontuar características e transformações do design na contemporaneidade e gerar argumentos favoráveis à inovação social e à sustentabilidade. Assim, criou-se uma base para geração de cenários futuros para a profissão e, também, para novas pesquisas acerca desses temas.

Palavras-chave: História do design. Design e participação. Inovação social.

\begin{abstract}
The design thinking and practice have changed a lot over time. However, diversity is featuring design today. This scenario, however, turn cloudy the responsibilities of design activities. From this issue, this paper seeks greater understanding of academic concerns in design with regard, mainly, to their purposes and adopted approaches. To achieve that, semi-structured interviews were conducted in order to generate an overview of the global design reality. After the data collection, analyzes were made in order to generate comparisons between the historical narrative of the profession and the current challenges in the area. Upon interpretation of preview analyzes, knowledge capable of point out characteristics and transformations of contemporary design were obtained, generating arguments for the social innovation and sustainability. Thus a basis for generating future scenarios for the profession and also for further research on these topics was created.
\end{abstract}

Keywords: Design History. Design as participation. Social innovation. 


\section{Introdução}

O design é uma atividade e área do conhecimento que explora a relação do ser humano com os artefatos e com a linguagem. O pensamento e a prática em design são capazes de articular e conceber tecnologias e significados que operam diretamente no cotidiano dos indivíduos. São itens e artefatos materiais e imateriais que se originam de um vasto conjunto de abordagens e de métodos criativos. É, dessa forma, que se torna cabível pontuar a relevância e a responsabilidade de designers e de pesquisadores no futuro das sociedades e, até mesmo, do planeta. E é em razão dessa responsabilidade que os movimentos da área, em direção a posturas mais críticas perante os contextos em que atua, têm sido cada mais recorrentes.

O design se transformou repetidamente durante sua história até o momento presente. No início, não se enxergavam as consequências e os efeitos das ações de projeto com os mesmos olhos de hoje. $O$ design como profissão surgiu durante a Revolução Industrial, entre os séculos XVIII e XIX, com o propósito de aumentar a qualidade dos produtos que estavam, à época, passando pelo processo de industrialização (CARDOSO, 2008). Os primeiros movimentos do design promoviam um resgate estético e a manutenção das relações antigas de trabalho. Já ao final do século XIX, os primeiros estilos internacionais surgiram e marcaram o início do período moderno.

Após a Segunda Guerra, o design começou a colaborar com outras áreas, como a comunicação e o marketing. Naquele período, o design influenciou o crescimento do consumismo e da obsolescência programada. Já a partir da década de 1960, relacionado ao surgimento da contracultura e dos ativismos político e ambiental, cria-se um cenário de mudança em toda a sociedade. Surge uma nova geração de designers, que rejeitaria os pensamentos praticados no Período entreguerras e iria em busca de novas definições para a atividade.

Pouco mais de duas décadas depois, o avanço tecnológico atinge um patamar significativo suficiente para mudar os indivíduos, a sociedade e, novamente, o design. As primeiras plataformas computacionais surgem e novas maneiras de se comunicar e de se relacionar impactam o comportamento e o pensamento humano. Isso leva o designer a direcionar as suas práticas projetuais aos "usuários". Estudos em ergonomia realizados décadas antes se misturam com estudos relacionados à percepção, à interação e à experiência humana. Áreas como a Psicologia começam a ser exploradas. Designers começam a se tornar especialistas em compreender as necessidades dos indivíduos e, também, em colaborar com eles na criação de soluções cada vez mais inovadoras.

Mesmo com uma observação breve da história do design, é possível notar como se intensificou a complexidade das relações de uso e de significado dos artefatos e dos processos criativos que os conceberam. Atualmente, tempo e espaço se confundem, e os efeitos da interação dos indivíduos com o mundo artificial são improváveis de prever, o que, consequentemente, gera novos desafios e problemas para o pensamento e a prática em design.

Como já mencionado, muito mudou desde a origem do design como profissão. Manzini (2016) argumenta que o os esforços de reflexão e de conduta se deslocaram do projeto de objetos (produtos, serviços e sistemas) em direção a maneiras de pensar e fazer (métodos, ferramentas e abordagens). $O$ pesquisador argumenta ainda que uma das principais mudanças é a de que, nos 
dias de hoje, todos os processos de design seriam atividades colaborativas que envolveriam uma grande variedade de atores sociais. Isso levaria o designer a se preocupar cada vez mais com o funcionamento, com o significado e com os efeitos dessas ações de colaboração. Nesse sentido, Slavin (2016) sugere que a criação de novos contextos e de plataformas para a participação seria um dos principais papéis do designer contemporâneo. $O$ autor argumenta, em favor dos impactos social e sustentável, que a abordagem do design voltada à participação influenciaria. Para Slavin (2016), é possível projetar para atender aos sistemas que permeiam a realidade de forma integral. Isso seria possível na medida em que projetistas focassem nas diferentes possibilidades de participação que os elementos de um sistema poderiam assumir entre si, no sentido de gerar valor ou resolver problemas. O autor sugere, em outras palavras, projetar não para os usos que se espera, mas para todos os usos que não se pode prever.

Nesta pesquisa se procura verificar, junto a pesquisadores e a acadêmicos de diferentes lugares do mundo, quais as linhas de pensamento que formulam os panoramas atual e futuro da área do design, principalmente no que diz respeito aos seus propósito e justificativa, bem como às suas abordagens e aos seus métodos.

\subsection{Os desafios do design contemporâneo}

A história do design não é simplesmente a história dos artefatos. Para Buchanan (1992), ela também passa pela transformação do pensamento em design, sendo os artefatos a expressão e a materialização desses pensamentos. O mesmo autor pontua que, na medida em que as décadas passaram-se, o pensamento e a prática em design foram tomando uma densidade e uma pluralidade cada vez maior. Há, hoje em dia, uma enorme diversidade de especializações e de braços profissionais na área. Possivelmente, essa situação seja um reflexo dos altos níveis de complexidade que se estabeleceram nas relações do homem com o mundo artificial nos últimos 30 anos. Mas, para compreender melhor como isso vem afetando atualmente o design, é preciso conceituar e esclarecer o conceito de complexidade.

Vassão (2010) entende que uma possível definição de complexidade poderia ser simplesmente aquilo que está além da compreensão. Outra definição, segundo esse mesmo autor, é a de que a complexidade poderia ser um conjunto de coisas simples que se acumulam e que seriam, portanto, percebidas como complexas pelo seu volume. Por último, Vassão (2010) define complexidade como aquilo que não pode ser disposto, apresentado ou compreendido como algo simples, que não pode ser decomposto em pedaços menores e que não pode ser reduzido.

Corrêa e Castro (2013) trazem o pensamento sobre a complexidade para o design, argumentando que a atividade é justamente complexa porque lida, o tempo todo, com uma grande diversidade de elementos diferentes (usuários, empresas, mercados, tecnologias, ambientes) e que, ao considerar apenas alguns desses elementos em detrimento de outros, sobrepondo os demais, acaba-se descartando a complexidade. Isso, para Corrêa e Castro (2013), limita a capacidade inventiva dos projetos e torna limitadas suas possibilidades. Ou seja, não seria possível, dessa maneira, solucionar problemas complexos de forma definitiva - em outras palavras, atender aos sistemas de forma integral. Os processos de design, segundo Corrêa e Castro (2013), devem ser encarados sem separações ou reduções, ou seja, a partir do paradigma da complexidade. 
De acordo com Vassão (2010, p. 13), "muitos entendem a atividade de design (projeto) como uma solução (resposta) para um problema (pergunta)". Mas à medida em que se aceita a complexidade em suas indeterminações, é possível perceber como é frágil a certeza de uma resposta ou solução finita, estanque. Talvez seja mais apropriado assumidamente "projetar perguntas" do que "projetar respostas" que, de definitivas, de fato, têm pouco.

Assim como a complexidade, os cenários social e ambiental atuais são questões desafiadoras para o design contemporâneo, sendo até mais urgentes e sensíveis do que o primeiro aspecto. Cardoso (2008) aponta que os primeiros designers a se preocuparem com questões ambientais surgiram nos anos 1960 e, em sua visão, a solução desses problemas passava necessariamente pelo redimensionamento das relações de consumo, especialmente, no sentido de ocorrer uma escolha individual em consumir menos e de modo mais consciente. Prontamente, pode-se entender que esse redimensionamento passa, também, por uma transformação de valores e de propósito da atividade de design. Castro (2008) aponta que o pensamento em design daquela década, embora partisse de uma crítica ao consumo, concentrava suas ações apenas no âmbito da produção - ao propor produtos recicláveis ou com matérias-primas alternativas, por exemplo -, deixando de abordar a demanda por mudanças de infraestrutura, de mercado, de cultura e de consumo.

Para Manzini (2008), a transição em direção a modos de vida mais sustentáveis seria um processo largamente difuso, o qual o autor chama de "aprendizagem social". Durante esse processo, diversificadas formas de criatividade, de conhecimento e de capacidades organizacionais emergiriam. $\mathrm{O}$ autor ainda aponta que esse processo seria facilitado por iniciativas locais capazes de romper padrões consolidados, principalmente, de consumo e de comportamento. Essas rupturas fazem parte do conceito de "inovação social" que, além disso, refere-se às transformações no modo em que indivíduos e comunidades resolvem seus problemas e criam novas oportunidades. Verifica-se a participação do designer nessas transformações justamente por ser um ator social que, prossegue Manzini (2008), lida com as interações cotidianas dos indivíduos com seus artefatos. E seriam precisamente essas interações, junto com as expectativas de bem-estar associadas a elas, que deveriam mudar durante a transição rumo a uma sociedade sustentável.

Manzini (2008) argumenta que os sistemas de produção e de consumo de uma sociedade sustentável serão profundamente diferentes daqueles que conhecemos, ao ponto que nenhuma alteração ou melhoramento parcial será suficiente. $O$ autor pontua que deverá haver uma grande redefinição do significado que cada indivíduo ou grupo atribui aos conceitos de qualidade de vida e de bem-estar. O problema estaria, entretanto, em como facilitar essa transição.

Para Castro (2008), uma nova geração de teóricos estaria propondo a substituição da ênfase do design no projeto de produtos pela busca da solução de problemas de uma forma alternativa. Para essa nova geração, as soluções não são necessariamente materializadas em produtos - como automóveis, máquinas de lavar ou embalagem de alimentos -, mas sim na forma de sistemas compartilhados com enfoque na sua expectativa de valor - como mobilidade, limpeza de roupas e entrega, armazenamento ou condicionamento de alimentos.

Esses conceitos remetem à ideia de design voltado à participação (SLAVIN, 2016), em que, em vez de se tentar controlar a complexidade com uma solução estanque, procura-se gerar valor na medida em que usuários adotam os problemas e criam friç̧ão entre os vários elementos de um 
sistema, tornando-se agentes de mudança. É dessa maneira que Manzini (2008) também conceitua iniciativas promissoras de inovação social: ao encontrar comunidades locais engajadas, nas quais aqueles que são diretamente afetados são também diretamente envolvidos nos projetos.

\section{Metodologia}

A fim de evidenciar e de validar as transformações do design enquanto atividade e área do conhecimento; de obter parâmetros para a prática e o pensamento em design dos próximos anos; e de estabelecer um panorama para a pesquisa e a crítica em design, foram realizadas entrevistas semiestruturadas com pesquisadores em design de vários lugares do globo. A amostragem fora definida com base nos artigos acadêmicos publicados e apresentados na conferência bienal da Design Research Society do ano de 2016 (Sociedade de Pesquisa em Design, em tradução livre).

A Design Research Society é uma sociedade com mais de 50 anos de história. A conferência se realizou em junho de 2016, na cidade de Brighton, na Inglaterra, com o tema "Future-Focused Thinking" (Pensamento Focado no Futuro, em tradução livre). Entendeu-se que, dada a realização recente da conferência e, principalmente, seu tema - similar ao que se propõe nesta pesquisa -, seria altamente relevante e pertinente basear a amostragem nos participantes do evento. Dessa maneira, foram enviados um total de 229 e-mails convidando todos aqueles que possuíam pesquisas publicadas nos anais da Design Research Society 2016 a participarem de uma entrevista sobre seus estudos e sobre assuntos relacionados à atividade do design. Ao final do processo de contato, 20 pessoas concordaram em realizar a entrevista, como lista o Quadro 1.

Quadro 1 - Lista de Entrevistados

\begin{tabular}{|c|c|c|c|}
\hline Sujeito & Nacionalidade & Formação & Área de atuação \\
\hline Entrevistado 1 & Dinamarca & Mestre em Ciências Sociais & Professor de Design e Gestão \\
\hline Entrevistado 2 & Inglaterra & PhD em Design & Professor de Design e Inovação \\
\hline Entrevistado 3 & Estados Unidos & Mestre em Arquitetura & Design de Interiores \\
\hline Entrevistado 4 & Grécia & Candidato a PhD em Design & Design de Serviço para a Sustentabilidade \\
\hline Entrevistado 5 & Noruega & PhD em Artes e Ofícios & Design e Aprendizagem \\
\hline Entrevistado 6 & Turquia & PhD em Design & Design e Educação, Ilustração \\
\hline Entrevistado 7 & Estados Unidos & PhD em História do Design & História e Reflexão em Design \\
\hline Entrevistado 8 & Escócia & PhD em Design & Saúde e Assistência Social \\
\hline Entrevistado 9 & Escócia & Doutorando em Engenharia & Design e Manufatura \\
\hline Entrevistado 10 & Coréia do Sul & PhD em Design & Inovação Interdisciplinar em Design \\
\hline Entrevistado 11 & Suécia & PhD em Inovação e Design & Design Participativo \\
\hline Entrevistado 12 & Trinidad e Tobago & Candidata a PhD & Design e Educação e Design Emancipatório \\
\hline Entrevistado 13 & Estados Unidos & Candidato a PhD & Design para Facilitação de Debates Públicos \\
\hline Entrevistado 14 & Canadá & Mestre em Design & Design de Jogos \\
\hline
\end{tabular}




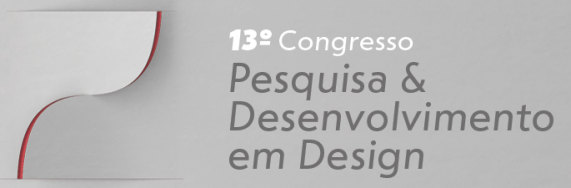

\section{Artigo Completo}

\begin{tabular}{llll}
\hline Entrevistado 15 & Estados Unidos & Doutora em Educação & Design Sistêmico e para a Sustentabilidade \\
\hline Entrevistado 16 & Holanda & Candidato a PhD & Co-design e co-criação \\
\hline Entrevistado 17 & Canadá & Mestre em Design & Comunicação Visual \\
\hline Entrevistado 18 & México & Mestre em Design Sustentável & Design para inovação social, design e democracia \\
\hline Entrevistado 19 & Inglaterra & PhD em Design & Design de Jogos e Design Especulativo \\
\hline Entrevistado 20 & Brasil & Doutorando em Design & Design Gráfico \\
\hline
\end{tabular}

Obteu-se um conjunto distinto de especialistas em design, que se propuseram a comentar, entre outros, os seguintes temas: o propósito atual de suas atividades em design; as principais responsabilidades e os desafios dessa área de atuação; as suas principais abordagens e os métodos projetuais; o caráter das soluções de projeto perante os atuais desafios da sociedade; suas preocupações em relação ao ambiente e a questões sociais; e suas expectativas para o futuro da profissão.

As entrevistas foram realizadas no formato de teleconferência, sendo possível, dessa maneira, explorar argumentos e posições, comparar e dialogar a respeito de pesquisas e de linhas de pensamento, além de trocar referências e ideias quanto aos meios profissionais e acadêmicos da área de design.

Depois de executadas, as entrevistas foram revisadas e ouvidas diversas vezes. No ato de revisão, foram transcritos os trechos e os conceitos mais interessantes de cada entrevista, sob a perspectiva dos pesquisadores. Assim, tornou-se possível trabalhar com os dados transcritos de formas visual e interativa, podendo ser realizados combinações, agrupamentos, categorizações e outros tipos de conexões entre os trechos. Esses esforços possibilitaram análises objetiva e integral do conteúdo abordado pelos entrevistados, permitindo que o entendimento do conteúdo implícito nas entrevistas se desenvolvesse de maneira racional.

Após, os resultados das análises e das interpretações da pesquisa foram arranjados em mapas conceituais. Segundo Amoretti (2001), mapas conceituais são redes semânticas representadas espacialmente nos termos de seus conceitos e relações. De acordo com Facca (2011), as diferentes representações visuais possibilitadas por mapas conceituais permitem estabelecer comparações e qualificações ao classificar os atributos mais importantes de determinado assunto, gerando uma visão ampla do cenário analisado. O resultado dessas análises, bem como a apresentação dos mapas conceituais, das ponderações dos pesquisadores e das suas relações com a bibliografia são descritos a seguir.

\section{Resultados e discussão}

\subsection{Análise de extremos}

Os primeiros resultados a serem discutidos se referem à análise e à comparação das entrevistas que apresentaram maior contraste no sentido do discurso e das ideias apresentadas. Tratam-se de sujeitos com nacionalidades diferentes, caracterizadas por contextos econômicos e sociais amplamente distintos. É notável a forma com que os ambientes profissional e acadêmico de cada um moldou seu desenvolvimento, sua linha de pesquisa e seu trabalho. 
De antemão, percebe-se que o Entrevistado 18 - Mestre em Design e de nacionalidade mexicana - discorre em sua entrevista principalmente sobre os aspectos políticos e sociais do design. Segundo ele, designers deveriam focar em "como podemos organizar nossas vidas de formas diferentes". O entrevistado conta que, atualmente, aplica seus esforços de pesquisa para entender como o design pode colaborar com outras áreas do conhecimento no projeto de um novo modelo de democracia. O Entrevistado 18 relata que, para isso, observa a interação de cidadãos de Auckland, Nova Zelândia, com um robô programado para fazer perguntas sobre política e democracia. O robô teria a intenção de concorrer a prefeito da cidade nas eleições de 2030 e, a partir dessa narrativa, diversos aspectos acerca do conhecimento e das opiniões políticas das pessoas são levantados. O Entrevistado 18 conta que, dessa forma, consegue obter dados valiosos e livres de preconceitos sobre assuntos que, em muitos casos, seriam tabus em uma conversa entre pessoas.

Em contrapartida, o Entrevistado 17 apresenta uma outra perspectiva sobre o design. É fácil perceber que este preocupa-se, principalmente, com a forma que a disciplina é abordada, em termos processuais e criativos. O Entrevistado 17 é canadense, Mestre em Design e possui seu próprio estúdio, no qual realiza principalmente projetos editoriais para organizações de médio e pequeno portes. O Entrevistado 17 acredita que o propósito do design é transferir significado, já que, para ele, "significado é uma preocupação em todas as disciplinas do design". Para serem assertivos nesse propósito, designers deveriam focar em eliminar o ruído dos códigos e dos canais ao triangular a forma com que projetam. Ou seja, designers deveriam embasar sua prática em pelo menos três fundamentações distintas. Para o Entrevistado 17, a ciência por trás da comunicação visual seria essencialmente uma dessas fundamentações, embora o projetista pudesse considerar os outros dois apoios conforme entenda necessário para cada situação. Estética e tecnologia seriam exemplos de fundamentações distintas da ciência, como exemplifica o Entrevistado 17.

O contraste entre esses pontos de vista pode ser analisado por alguns conceitos históricos de design. Verifica-se na fala do Entrevistado 17, por exemplo, o pensamento e o desejo de trazer a ciência para perto do design, tornando-o racional e objetivo. Essa mesma visão foi compartilhada entre os designers da última fase da Bauhaus, como Theo Van Doesburg (CROSS 2001). De fato, é fácil entender que o Entrevistado 17 vê que a forma - elementos gráficos e visuais, no seu caso em particular - deve seguir a função (transferir significado). O que se percebe nessa entrevista, entretanto, é que o Entrevistado 17 não vê a ciência como algo dogmático para a prática de design, diferentemente de Van Doesburg, que defendia a utilização de um método definitivo (CROSS, 2001).

O entrevistado canadense exemplifica seu ponto de vista pontuando uma possível contribuição da ciência para a prática do design: concluir cientificamente que um enunciado escrito em determinada tipografia se torna ilegível. Ou seja, segundo o Entrevistado 17, designers poderiam fazer uso de métodos e de abordagens da ciência para obter conhecimentos relativamente acessíveis e aplicá-los de forma pragmática. Seria possível, então, convencer o cliente que utilizar a tipografia em questão não permite a tranferência do significado da mensagem e, logo, eliminar o ruído do código. Essa visão não se configura como dogmática pois apenas utiliza a ciência em benefício do design, não descaracterizando quaisquer outras referências ou técnicas aplicadas ao processo criativo. Em nenhum momento, o Entrevistado 17 explana sobre restringir o design a formas geométricas, a cores ou a tipografias específicas, como 
na escola alemã citada anteriormente (CARDOSO, 2008).

É possível verificar, entretanto, que as condições do problema exemplificado pelo canadense são relativamente isoláveis e mensuráveis, diferentemente das indeterminações dos problemas complexos relatadas por Buchanan (1992) e exploradas nas pesquisas do Entrevistado 18. Segundo Buchanan (1992), é perceptível a evolução do design de artefatos físicos ou gráficos para o design de serviços ou sistemas, por exemplo. Estes últimos, invariavelmente, relacionam-se com uma complexidade maior que os primeiros. Logo, é possível entender que enquanto os problemas sejam técnicos e isoláveis seria possível fazer design com ciência - como sugere o Entrevistado 17 -, mas o mesmo não ocorre com problemáticas complexas. A criação de novos modelos de democracia, pesquisa do Entrevistado 18, ilustra a seguir essa diferença.

Para o entrevistado mexicano, o design com fins sociais não funciona sugerindo soluções de forma empírica, como um cientista em seu laboratório de condições controláveis. Design social, sob a perspectiva do entrevistada 18 , teria relação com compreender as situações e as correlações do problema em questão e atuar na solução dos sintomas. Vassão (2010) concordaria que essa abordagem - de reduzir algo complexo em partes, ou, no caso, em sintomas - não é definitiva mas é, contudo, uma maneira de lidar com a complexidade natural dos problemas sociais de hoje. Para o Entrevistado 18, não se faz design social criando e produzindo novos artefatos pois, em essência, o design social teria relação com a interação que ocorre por meio de artefatos e não com os artefatos em si. Esse argumento remete à obra de Manzini (2008), que comenta, justamente, que designers seriam responsáveis pelas interações cotidianas dos indivíduos. Remete, também, às proposições de Slavin (2016), que sugere projetar a participação das pessoas com os sistemas ao seu entorno através dos artefatos - não projetar o artefato em si.

Ficam claras, a partir desses comentários, as indeterminações de projetos sob a ótica do design social. A interação interpessoal ocorre de maneiras distintas ao redor do mundo e depende da cultura e do contexto dos povos e das nações, entre outras coisas. Logo, não é isolável. Ainda, seus efeitos não seriam possíveis de serem medidos ou acompanhados com precisão, ou seja, justamente o oposto ao exemplo da tipografia trazido pelo Entrevistado 17.

Em sua fala, o Entrevistado 18 ainda aponta que há, atualmente, muito interesse pelo design social. Entretanto, pouco realiza-se, de fato. Segundo ele, deve-se debater mais sobre as falhas dessa área para criar conhecimentos mais profundos e assertivos sobre as melhores práticas. Nesse ponto, o Entrevistado 18 cita o trabalho de Ezio Manzini como uma das principais referências em design para inovação social.

Exploradas essas duas perspectivas do design é possível dizer que, de certa forma, são distantes entre si, mas não são necessariamente contrárias ou excludentes. O que é visível é que as duas lidam com situações completamente distintas: uma, relacionada com práticas mais típicas e tradicionais do design, que teriam origem em épocas passadas; e, a outra, contemporânea, que se relaciona com desafios mais amplos, que lida com incertezas e que sugere o projeto de interações sociais e não de funcionalidades. Percebe-se, assim, que o design evoluiu e transformou-se, mas que essas mudanças não substituíram as práticas e os pensamentos passados e, sim, foram somadas a eles, tornando mais densa e complexa essa área do conhecimento. 


\subsection{Sobre propósito, causas e efeitos}

Ao se analisar em conjunto diversos trechos de discursos dos entrevistados, fica claro que o pensamento em design da atualidade está se propondo a criar soluções que objetivam o benefício das pessoas e das comunidades de forma generalizada (e não de um único usuário ou sujeito consumidor). Logo, há um consenso entre os entrevistados sobre essa ideia como uma das recentes atribuições da profissão. Também é claro que há uma preocupação maior em relação aos efeitos que soluções de projeto despertam ou causam nas pessoas e no ambiente em detrimento das preocupações passadas, limitadas às formas funcionais dessas soluções, ou, ainda, às suas potencialidades mercadológicas.

Em parte, essas características concedidas ao propósito do design contemporâneo se relacionam com a filosofia de um dos movimentos precursores da área. Durante o movimento conhecido como Arts and Crafts, propagava-se que o modo de organização do trabalho era o responsável pela decadência dos objetos da época (CARDOSO, 2008). Nessas ideias se evidencia o valor que tal movimento dava às pessoas e, mais especificamente, aos designers. Mozota (2011) argumenta, em sentido similar, que os seguidores do Arts and Crafts entendiam os artefatos como entidades abstratas que se envolviam com circunstâncias sociais. Essa característica pode ser relacionada com o discurso dos entrevistados em razão do efeito (e não da funcionalidade) dos artefatos no mundo.

Cardoso (2008) reforça que designers e pensadores ligados ao Arts and Crafts pregavam que o poder do designer de alterar a sociedade residia, de fato, mais nas formas das suas relações de trabalho do que nas formas que estes atribuíam aos artefatos. Esse pensamento evoluiu e se tornou mais amplo: hoje, é possível dizer que, com base na análise das entrevistas, o poder do designer de alterar a sociedade reside nas formas com que promove a relação e a colaboração entre os indivíduos por meio dos artefatos que projeta.

Analisando o mesmo conjunto de trechos das entrevistas, é possível perceber ainda que os designers estão, de forma sistemática, substituindo "funcionalidade" por "função social", da mesma forma que Victor Papanek havia sugerido há, aproximadamente, 50 anos (CARDOSO, 2012). Porém, como pontua Margolin (2002), as explanações de Papanek não resultaram em novos modelos de prática profissional. Entretanto, percebe-se, por meio desta pesquisa, que esse cenário possa estar mudando logo que o conteúdo e os discursos analisados indicam que as preocupações sobre as responsabilidades (no caso, os efeitos desencadeados pelos projetos) do design parecem ter tomado uma forma mais consistente e urgente perante a prática e o pensamento atual.

\subsection{Sobre abordagens e soluções projetuais}

Segundo o Entrevistado 19, PhD, designer de jogos e pesquisador britânico, designers de vanguarda se preocupam, hoje, em projetar a participação dos usuários e dos artefatos com os sistemas que os entornam; preocupam-se em visualizar usuários não como o centro dos sistemas, mas como um elemento de igual valor que os demais; e se preocupam em transformar a passividade em atividade (ou participação).

Seguindo as análises dos discursos dos entrevistados sobre o tema deste subcapítulo, percebe-se diversas falas que discorrem em razão de métodos e de abordagens projetuais 
holísticas e divergentes em detrimento de métodos e de práticas limitadoras ou definitivas. Da mesma forma, há mais densidade de conteúdo acerca de valores e de soluções imateriais, como sistemas de colaboração, conjuntos de interações e de significados, do que a respeito de bens de consumo, objetos e outros artefatos tangíveis.

$\mathrm{Na}$ história do design, o projeto de artefatos imateriais (como mensagens e significados) existe desde muito cedo. Na Werkbund alemã do início do século XX, por exemplo, os produtos finais eram a "identidade" e a "diferenciação", mesmo que se manifestassem por meio de objetos físicos (CARDOSO, 2008). Da mesma forma, movimentos como o Art Nouveau sustentavam valores imateriais como sofisticação e originalidade. Ainda, especialidades da área que se desenvolveram muito nessa mesma época, como design de identidades visuais corporativas e o design gráfico, têm em sua essência o manejo da imaterialidade.

A transformação mais substancial destacada por este segundo conjunto de análises se faz presente na maneira com que designers vêm encarando os desafios projetuais. Inúmeras entrevistas evidenciam a adoção da complexidade e suas incertezas. Hoje, como os entrevistados indicam, são valorizadas abordagens sistêmicas que consideram um enorme e vasto conjunto de fatores. No último século e meio, todavia, encontram-se em inúmeras ocasiões esforços em reduzir e em limitar a abrangência do design. O movimento modernista como um todo, por exemplo, objetivava definir e restringir a prática de design dessa ou daquela maneira, alegando seus dogmas como os únicos verdadeiros. Verificam-se essas circunstâncias também no funcionalismo dos anos finais de Bauhaus, por exemplo, em movimentos como o De Stijl, novamente no neofuncionalismo e até mesmo no styling, que limitava o design como um instrumento de vendas (CARDOSO, 2008).

Mais recentemente, verifica-se uma tentativa de limitar as abordagens da atividade do design pelos métodos centrados no usuário. Slavin (2016) argumenta que esse tipo de abordagem torna os designers cegos, forçando-os a projetar exclusivamente para os usuários sob uma ótica de consumo. Esse ponto de vista é levantado em numerosas entrevistas, como na dos Entrevistados 2, 19 e 17. Observa-se então que, mesmo o design centrado no usuário estar em voga nas áreas profissionais do design, a pesquisa acerca desse tema já começa a questionar seu valor em relação a suas características limitadoras.

Em outras palavras, o que esses pesquisadores argumentam é que designers devem sim projetar para os usuários, mas não como consumidores e sim como pessoas. Pessoas que, por sua vez, habitam um mundo onde existem redes de artefatos e de informações, ecossistemas ambientais e urbanos, política, economia e riqueza, mas também carências financeira e de recursos materiais. O profissional de design teria a responsabilidade, segundo a fala dos entrevistados, de balancear a complexidade de todos esses aspectos. A incidência de trechos e de falas nas entrevistas que trazem ideias sobre as abordagens acima apresentadas indicam que há um forte movimento nessa direção, o que pode validar uma afirmação de Cardoso (2008), a qual diz que pela primeira vez, nos últimos dois séculos, ambos, designers e sociedade, estão dispostos a conviver com a complexidade ao invés de combatê-la. 


\subsection{Sobre complexidade e design com fins sociais}

A última etapa das análises busca relacionar e dar sentido aos discursos sobre trechos e falas que abordam a complexidade e o design social de forma direta. A primeira observação destacada nesse conjunto de trechos foi a grande variedade e divergência de ideias e de discursos, em comparação com os demais conjuntos descritos e comentados anteriormente. Essa constatação pode levar a entender que esses assuntos são mais confusos, menos claros e de menor domínio dos entrevistados. Ou pode revelar, ainda, que esses assuntos, por mais que sejam de domínio dos entrevistados, têm uma natureza indeterminante, já que lidam com questões relacionadas aos problemas sociais do mundo e a complexidade em si.

Entretanto, mesmo com a grande variedade citada, há comentários ou ideias que se assemelham entre si, sugerindo pelo menos três linhas de pensamento distintas sobre os temas desta seção.

O primeiro conjunto sugere que é possível gerar impacto social positivo ou alcançar a sustentabilidade mesmo projetando nos mesmos modelos que se conhece. Seria necessário, no entanto, um reenquadramento da pesquisa e da prática em design. O Entrevistado 1 sugere em sua fala, por exemplo, que objetos podem ser resilientes como pessoas, se projetados para serem assim. Uma das formas de fazer isso, segundo o pesquisador, seria criar objetos com altos valores simbólico e sentimental, ricos em significados e associações. O Entrevistado 1 defende que essa atitude desaceleraria o consumo e o descarte de materiais. Nesse mesmo conjunto de comentários podem ser encontradas ideias que sugerem reeducação cultural no que diz respeito ao comportamento de consumo.

Um outro conjunto de trechos narra certas distorções éticas da profissão, muito ligadas ao uso irresponsável de materiais e ao caráter demasiadamente comercial que uma boa parcela dos designers assume - às vezes, coercitivamente. Contudo, à época das origens da profissão, o propósito desta era justamente tornar esses produtos os mais atrativos ao consumidor. Schneider (2010) comenta que, à época da origem da profissão, os designers foram rapidamente reconhecidos pelo seu potencial para aumentar as vendas. Essa proximidade com o mercado e com as circunstâncias comerciais dos artefatos segue ao longo de toda a história do design. Em alguns momentos, acentua-se de formas similares às ocorridas em sua origem, como durante o movimento styling (CARDOSO, 2008), e novamente nos anos 1980 e 1990, de acordo com a perspectiva proporcionada na entrevista do Entrevistado 8.

O terceiro conjunto traz trechos que relatam como os pesquisadores estão criando soluções e inovações sociais disruptivas, ou seja, que propõem novos modelos ou que descontroem os em voga. É clara a influência de autores como Manzini (2008) e Slavin (2016) nesse conjunto de ideias. Entretanto, entende-se que as propostas que ali se encontram ainda são, de certa forma, utópicas, logo porque demandam mudanças drásticas em muitas áreas do conhecimento e da sociedade. Em contrapartida, pode-se entender que ainda há muito espaço para a criação de novas intervenções e de abordagens às sustentabilidades social e do ambiente, uma vez que não há incidência de trechos ou de falas que pontuam essas ações disruptivas como propulsoras de qualquer tipo de impacto negativo. Contudo, para que soluções dentro desse domínio se façam úteis, ainda é necessário projetos com maior aplicabilidade ou mais próximos às realidades de hoje. 


\subsection{Ilustrando o vetor da transformação do design}

Após categorização, observação e análise de trechos significativos das entrevistas, foi proposta a criação de um mapa conceitual no formato de um diagrama de valores. Esse mapa (Figura 1) objetiva ilustrar o resultado das análises em comparação ao pensamento e à prática em design estudados e revisados nas bibliografias.

Figura 1 - Mapa da transformação do design

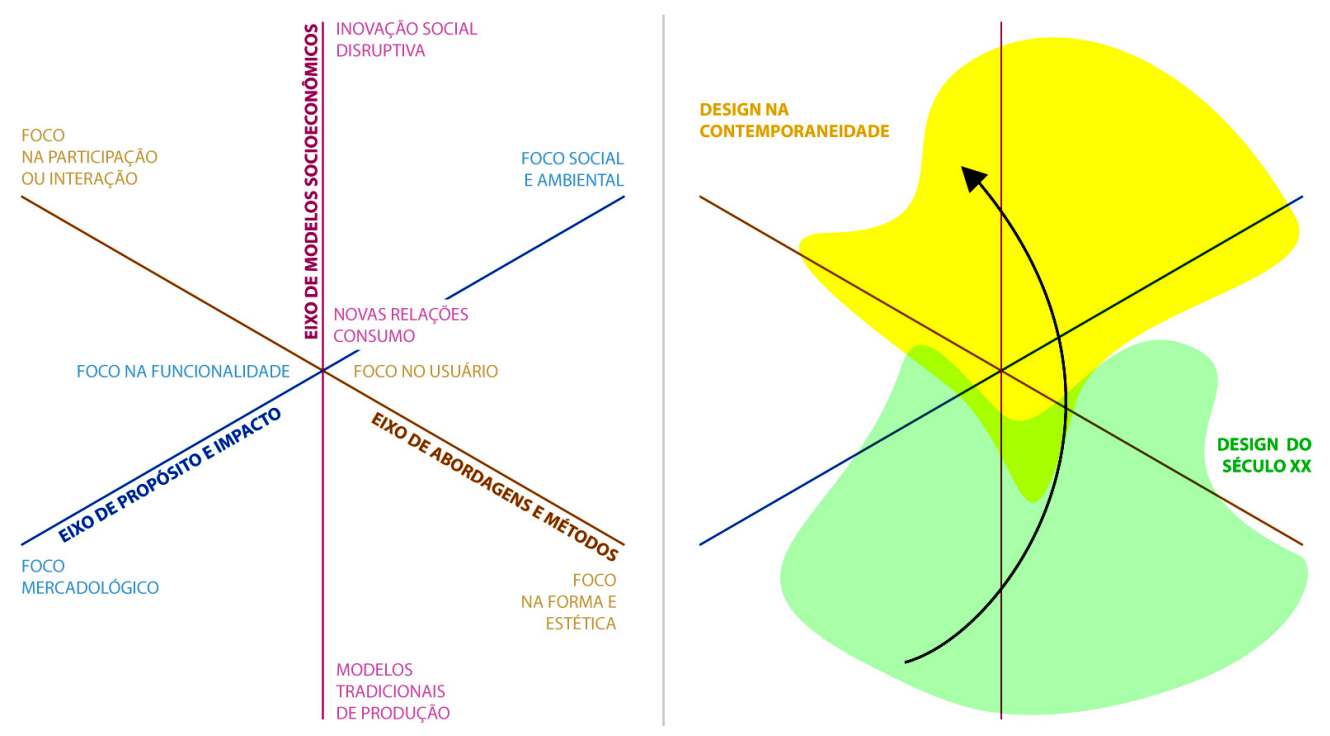

Fonte: do autor

Os motes abordados nesta pesquisa definiram os eixos de valores do mapa (mapa da esquerda). De forma complementar, a revisão bibliográfica e as análises das entrevistas possibilitaram posicionar dois grandes momentos distintos na transformação do design (mapa da direita). Um deles, ilustrado pela mancha esverdeada, é caracterizado pelo foco no projeto de objetos materiais, de alto valor mercadológico, em que a sua configuração formal e os modelos de produção e de industrialização vigentes norteavam a prática e o pensamento em design. $O$ outro momento, ilustrado pela mancha amarelada - que ocorre há pelo menos 30 anos e que ainda hoje se desenvolve -, é caracterizado por linhas de pesquisa focadas na sustentabilidade, no usuário como sujeito ativo nos ambientes e também em modelos socioeconômicos baseados em inovação e disrupção em relação aos modelos passados.

O vetor de mudança no pensamento e na pesquisa em design, ilustrado no mapa da direita (seta preta), sugere que a complexidade e a subjetividade estarão cada vez mais presentes em pesquisas da área, uma vez que conceitos como participação e inovação social essencialmente rementem a novas maneiras de pensar e fazer: maneiras sistêmicas, integrais e abrangentes. Designers precisam se preparar, nesse sentido, para lidar com os desafios que estão por vir para que possam, cada vez mais, impactar positivamente os contextos e onde atuam.

É importante pontuar que o resultado desses diagramas tem como base, além das análises objetivas - de conteúdo explícito das entrevistas -, a análise e a percepção do conteúdo implícito das entrevistas. Ainda, este resultado é fundamentado quase que exclusivamente na área 
acadêmica do design (na medida em que todos os entrevistados são acadêmicos, sendo alguns também atuantes nos respectivos mercados de trabalho de seus países). Esse fato abre espaço para divergências em relação às transformações do design, principalmente no que diz respeito aos âmbitos profissional e de mercado.

\section{Considerações finais}

O design, como visto, desdobra-se e se manifesta de maneiras distintas e, eventualmente, opostas e paradoxais. Os conteúdos deste trabalho, no entanto, permitiram compreender essa área do conhecimento de forma ampla, bem como permitiram observar que ainda há o que ser explorado e descoberto no design.

O objetivo do presente trabalho foi estabelecer um panorama global acerca da atividade e, principalmente, da pesquisa em design. Para isso, pesquisou-se temas relacionados às práticas adotadas, aos pensamentos idealizados e, em última instância, ao propósito compartilhado entre os indivíduos que pertencem à comunidade acadêmica mundial de design. Para gerar este variado e extenso volume de informações, uma série de análises foi realizada. A partir dessas análises, foi possível compreender de maneira crítica algumas das causas e dos efeitos da atuação dos designers na contemporaneidade.

Ao final deste estudo, é possível concluir que a atividade de design está passando por um período de transformação, caracterizado pela desvalorização de abordagens reducionistas e primando pela visão sistêmica e pelo tratamento holístico dos problemas que está se propondo solucionar. Este período de transformação também pode ser definido pelo desenvolvimento dos valores da área no que diz respeito às suas responsabilidades éticas: designers estão assumindo que seu propósito estaria intimamente ligado aos efeitos de suas criações no mundo e, em função disso, devem se preocupar com as sustentabilidades social e ecológica ao projetarem, em detrimento de fatores comerciais ou estilísticos, por exemplo. Essa jornada de transformação, no entanto, é longa e gradual, pois se verificou que o debate sobre as abordagens e sobre a ética do design ocorre há muitas décadas. O que esta pesquisa indica, na verdade, é que esse debate pode estar evoluindo para um teor menos filosófico e mais prático, seja no meio acadêmico ou no profissional.

O caráter qualitativo desta pesquisa indica que o que foi argumentado aqui foi fruto de interpretações e de ponderações embasadas na perspectiva dos pesquisadores, nas referências expostas e nos dados coletados. Há espaço nesta pesquisa para aprofundar as relações criadas. Cabe, por exemplo, a criação de relações entre a origem dos entrevistados e as situações sociais, políticas e econômicas de seus respectivos países para justificar escolhas por determinadas posturas e valores perante a disciplina. Ainda, é possível realizar a análise dos dados de inúmeras outras formas e métodos.

Reconhece-se, nesse ponto, que os dados coletados nas entrevistas são suficientes para que outros e mais apurados métodos de análise sejam aplicados. Esta pesquisa suscita novas abordagens e desdobramentos, seja trazendo a perspectiva de um maior número de designers com repertórios e especialidades ainda mais distintos no contexto acadêmico e também com maior representatividade no contexto de mercado -, seja ampliando seu caráter até níveis quantitativos ou ainda conectando e relacionando abordagens quantitativas e qualitativas. 
Conclui-se argumentando, em razão da facilitação das transformações e da evolução do pensamento e da prática em design, que este deve se configurar em uma área do conhecimento útil aos seres humanos e ao planeta, plena em seus valores e abordagens e escalável em seu potencial como agente de novas transformações. Em parte, é responsabilidade dos designers, enquanto especialistas do mundo artificial, de suas ferramentas, interações, soluções e, principalmente, de seus problemas, propor e sugerir as mudanças necessárias à criação de um mundo melhor para todos.

\section{Referências}

AMORETTI, M. S. M. Protótipos e estereótipos: aprendizagem de conceitos - Mapas Conceituais: experiência em Educação a Distância. Informática na Educação: Teoria \& Prática, Porto Alegre, v. 4, p. 49-55, dez. 2001.

BUCHANAN, Richard. Wicked problems in design thinking. Design Issues, Cambridge, n.2, p. 5-21, Spring 1992.

CARDOSO, Rafael. Uma introdução à história do design. São Paulo: Blucher, 2008.

. Design para um mundo complexo. São Paulo: Cosac Naify, 2012.

CASTRO, Maria Luiza A. C. Da ética construtivista à ética sustentável: a trajetória do design. Faculdade de Arquitetura e Design de Interiores da Universidade Federal de Uberlândia, Cadernos de Pós-Graduação em Arquitetura e Urbanismo, v.1, p. 122-132, 2008.

CORRÊA, G. R.; CASTRO, M. L. A. C. O Pensamento Complexo de Edgar Morin e o Design. Revista Estudos em Design, Rio de Janeiro, v. 21, p. 01-15, 2013.

CROSS, Nigel. Designerly ways of knowing: design discipline versus design science. Design Issues, n.3, p. 49-55, Summer 2001.

FACCA, Cláudia Alquezar. O designer como pesquisador: uma abordagem metodológica da pesquisa aplicada ao design de produtos. São Paulo: Blucher Acadêmico, 2011.

MANZINI, Ezio. Design para a inovação social e sustentabilidade: comunidades criativas, organizações colaborativas e novas redes projetuais. Rio de Janeiro: E-papers, 2008.

. Design Culture and Dialogic Design. Design Issues, Cambridge, n.1, p. 52-59, Winter 2016.

MARGOLIN, Victor. The Politics of the Artificial. Essays on Design and Design Studies, Chicago: The University of Chicago Press, 2002.

MOZOTA, Brigitte Borja de. Gestão do design: usando o design para construir valor de marca e inovação corporativa. Porto Alegre: Bookman, 2011.

SCHNEIDER, Beat. Design - Uma introdução: o design no contexto social, cultural e econômico. São Paulo: Editora Blucher, 2010.

SLAVIN, Kevin. Design as participation. Journal of Design and Science. MIT Press, 2016.

VASSÃO, Caio Adorno. Metadesign: ferramentas, estratégias e ética para a complexidade. São Paulo: Blucher, 2010. dal 